\title{
Adenosine Receptor Signaling Modulates Permeability of the Blood-Brain Barrier
}

\author{
Aaron J. Carman, Jeffrey H. Mills, Antje Krenz, Do-Geun Kim, and Margaret S. Bynoe \\ Department of Microbiology and Immunology, Cornell University, College of Veterinary Medicine, Ithaca, New York 14853
}

The blood-brain barrier (BBB) is comprised of specialized endothelial cells that form the capillary microvasculature of the CNS and is essential for brain function. It also poses the greatest impediment in the treatment of many CNS diseases because it commonly blocks entry of therapeutic compounds. Here we report that adenosine receptor (AR) signaling modulates $B B B$ permeability in vivo. $\mathrm{A}_{1}$ and $\mathrm{A}_{2 \mathrm{~A}}$ AR activation facilitated the entry of intravenously administered macromolecules, including large dextrans and antibodies to $\beta$-amyloid, into murine brains. Additionally, treatment with an FDA-approved selective $\mathrm{A}_{2 \mathrm{~A}}$ agonist, Lexiscan, also increased $\mathrm{BBB}$ permeability in murine models. These changes in $\mathrm{BBB}$ permeability are dose-dependent and temporally discrete. Transgenic mice lacking $\mathrm{A}_{1}$ or $\mathrm{A}_{2 \mathrm{~A}} \mathrm{ARs}_{\mathrm{B}}$ showed diminished dextran entry into the brain after AR agonism. Following treatment with a broad-spectrum AR agonist, intravenously administered anti- $\beta$-amyloid antibody was observed to enter the CNS and bind $\beta$-amyloid plaques in a transgenic mouse model of Alzheimer's disease (AD). Selective AR activation resulted in cellular changes in vitro including decreased transendothelial electrical resistance, increased actinomyosin stress fiber formation, and alterations in tight junction molecules. These results suggest that AR signaling can be used to modulate BBB permeability in vivo to facilitate the entry of potentially therapeutic compounds into the CNS. AR signaling at brain endothelial cells represents a novel endogenous mechanism of modulating BBB permeability. We anticipate these results will aid in drug design, drug delivery and treatment options for neurological diseases such as AD, Parkinson's disease, multiple sclerosis and cancers of the CNS.

\section{Introduction}

The blood-brain barrier (BBB) is comprised of brain endothelial cells (BECs), which form the lumen of the brain microvasculature (Abbott et al., 2010). The barrier function is achieved through tight junctions between endothelial cells that regulate the extravasation of molecules and cells into and out of the CNS (Abbott et al., 2010). Although the BBB serves to restrict the entry of potentially toxic substances into the CNS, it poses a tremendous hurdle to the delivery of therapeutic drugs into the CNS. It has been estimated that $>98 \%$ of small-molecule drugs $<500 \mathrm{Da}$ in size do not cross the BBB (Pardridge, 2001, 2005). Current approaches aimed at altering the BBB to permit the entry of therapeutics are either too invasive, too painful, can result in permanent brain damage or result in loss of drug efficacy (Hanig et al., 1972; Broadwell et al., 1982; Rapoport, 2001; Bidros and Vogelbaum, 2009; Hynynen, 2010). There is a monumental need to modulate the $\mathrm{BBB}$ to facilitate the entry of therapeutic drugs into the CNS. Determining how to safely and effectively do this could

\footnotetext{
Received June 30, 2011; revised July 26, 2011; accepted July 28, 2011

Author contributions: A.J.C., J.H.M., M.S.B., and A.K. designed research; A.J.C., J.H.M., M.S.B., A.K., and D.-G.K. performed research; A.J.C., J.H.M., M.S.B., A.K., and D.-G.K. analyzed data; A.J.C., J.H.M., M.S.B., and A.K. wrote the paper.

This work was supported by National Institutes of Health Grants R01 NS063011 (to M.S.B.) and F32 NS 066682 (to J.H.M.).We acknowledge Dr. Chris Schaffer of Cornell University for the AD transgenic mice, Dr. Helen Marquis for her critical reading of the manuscript, and Delbert Abi-Abdallah for help with Western blotting. We also acknowledge Adenios, Inc. for their kind gift of the anti- $\beta$-amyloid antibody.

The authors declare no competing financial interests.

Correspondence should be addressed to Margaret S. Bynoe at the above address. E-mail: msb76@cornell.edu. DOI:10.1523/JNEUROSCI.3337-11.2011

Copyright $\odot 2011$ the authors $\quad 0270-6474 / 11 / 3113272-09 \$ 15.00 / 0$
}

greatly benefit a broad range of neurological diseases, such as Alzheimer's disease (AD), Parkinson's disease, multiple sclerosis, neurological manifestations of acquired immune deficiency syndrome (AIDS), CNS cancers, and many more. Promising therapies are available to treat some of these disorders, but their potential cannot be fully realized due to the tremendous impediment posed by a functional BBB. Here, we provide novel data demonstrating that signaling through receptors for the purine nucleoside adenosine acts as a potent, endogenous modulator of BBB permeability.

It is well established that adenosine has many diverse roles in mammalian physiology, including immunomodulatory roles regulating immune cell responses (Bours et al., 2006; Kobie et al., 2006; Deaglio et al., 2007) and roles in proper CNS functioning (Sebastião and Ribeiro, 2009; Stone et al., 2009). The first clues to adenosine's involvement in CNS barrier permeability came from our recent findings demonstrating that extracellular adenosine, produced by the catalytic action of CD73 (a 5 '-ectonucleotidase) from AMP, promotes lymphocyte entry into the CNS in experimental autoimmune encephalomyelitis (EAE) (Mills et al., 2008). These studies demonstrated that mice lacking CD73 (Thompson et al., 2004), which are unable to produce extracellular adenosine, are protected from EAE and that blockade of the $\mathrm{A}_{2 \mathrm{~A}}$ adenosine receptor (AR) inhibits $\mathrm{T}$ cell entry into the CNS (Mills et al., 2008). These observations led us to hypothesize that modulation of AR signaling at BECs might modulate BBB permeability to facilitate the entry of molecules and cells into the CNS. Indeed, our results suggest that AR signaling represents a novel, endogenous modulator of BBB permeability. 


\section{Materials and Methods}

Mouse and rat models. C57BL/6 mice (Jackson Laboratories) were used as WT. $A_{1}{ }^{-1-}$ AR mice were a gift from Dr. Jurgen Schnermann (NIH/NIDDK, Bethesda, MD) (Sun et al., 2001). $A_{2 \mathrm{~A}}^{-1-}$ AR were a gift from Dr. Jiang-Fan Chen (Boston University School of Medicine, Boston, MA) (Chen et al., 1999). The transgenic AD mice [B6.Cg$\mathrm{Tg}$ (APPswe,PSEN1dE9)85Dbo/J] were a gift from Dr. Chris Schaffer (Cornell University, Ithaca, NY) (Jankowsky et al., 2004). Typically, mice were aged 7-9 weeks and weighed between 20 and 25 g. Sprague Dawley rats (Charles River Laboratories) were female, aged 8 weeks and weighed 200220 g. Animals were bred and housed under specific pathogen-free conditions at Cornell University, Ithaca, NY. All procedures were done in accordance with approved Institutional Animal Care and Use Committee protocols.

Administration of drugs and tissue collection. NECA [1-(6-amino$9 H$-purin-9-yl)-1-deoxy- $N$-ethyl- $\beta$-D-ribofuranuronamide], CCPA (2-chloro- $N^{6}$-cyclopentyladenosine), CGS 21680 (4-[2-[[6-amino-9-( $N$ ethyl- $b$-D-ribofuranuronamidosyl)- $9 H$-purin-2 yl] amino] ethyl] benzenepropanoic acid), and SCH 58261 (5-amino-7(phenylethyl)-2-(2furyl)-pyrazolo[4,3-e]-1,2,4-triazolo[1,5-c]-pyrimidine) (Tocris Bioscience) were each dissolved in DMSO then diluted in PBS to the desired concentration; in most cases final DMSO concentrations were $<0.5 \%(\mathrm{v} / \mathrm{v})$. Lexiscan (regadenoson; Toronto Research Chemicals) was dissolved in PBS. For vehicle controls, DMSO was diluted in PBS to the same concentration. Dextrans labeled with either FITC or Texas Red (Invitrogen) were suspended in PBS to $10 \mathrm{mg} / \mathrm{ml}$. Experiments involving dextran injection used $1.0 \mathrm{mg}$ of dextran in PBS. When drug and dextran were injected concomitantly, $1.0 \mathrm{mg}$ of dextran was mixed with the drug to the desired concentration in a final volume of $200 \mu$ l. All injections except injections of SCH 58261 were retro-orbital intravenous. Lexiscan was administered intravenously with 3 injections, 5 min apart, and tissues were collected at 15 min unless otherwise indicated. In dose-response experiments, drugs and dextrans were injected concomitantly. SCH 58261 injections, $1 \mathrm{mg} / \mathrm{kg}$, were intraperitoneal and mice were predosed with this concentration daily for $4 \mathrm{~d}$ before the day of the experiment. An additional injection was administered at the time of the experiment. At indicated times mice were anesthetized and perfused with cold PBS through the left ventricle of the heart. Brains were weighed and frozen for later analysis.

Fluorimetric analysis. Tris-Cl, $50 \mathrm{~mm}, \mathrm{pH} 7.6$, was added to brains (100 $\mu \mathrm{l}$ per $100 \mathrm{mg}$ brain). Brains were homogenized with a Dounce homogenizer and centrifuged at $16.1 \times g$ for $30 \mathrm{~min}$. Supernatants were transferred to new tubes and an equal volume absolute methanol was added. Samples were centrifuged at $16.1 \times g$ for $30 \mathrm{~min}$. Supernatant $(200 \mu \mathrm{l})$ was transferred to a Corning Costar 96 well black polystyrene assay plate (clear bottom). A series of standards containing $0.001-10 \mu \mathrm{g} / \mathrm{ml}$ dextran in $50 \%$ Tris- $\mathrm{Cl} / 50 \%$ absolute methanol (v/v) was added to each plate. Absolute concentrations of dextrans were derived from these standard curves. Fluorimetric analysis was performed on a BioTek Synergy 4.

Primary brain endothelial cell isolation. This method has been adapted from previously described techniques (Song and Pachter, 2003). Briefly, 12-week-old C57BL/6 mice were killed and decapitated. Dissected brains were freed from the cerebellum and large surface vessels were removed by carefully rolling the brains on sterile Whatman paper. The tissue was then homogenized in a Dounce homogenizer in ice-cold DMEM-F12 medium, supplemented with L-glutamine and Pen/Strep, and the resulting homogenate was centrifuged at $3800 \times g, 4^{\circ} \mathrm{C}$ for $5 \mathrm{~min}$. After discarding the supernatant, the pellet was resuspended in $18 \%(\mathrm{w} / \mathrm{v})$ dextran in PBS solution, vigorously mixed, and centrifuged at $10,000 \times \mathrm{g}, 4^{\circ} \mathrm{C}$ for 10 $\min$. The foamy myelin layer was carefully removed with the dextran supernatant by gentle aspiration. The pellet was resuspended in prewarmed $\left(37^{\circ} \mathrm{C}\right.$ ) digestion medium (DMEM supplemented with $1 \mathrm{mg} / \mathrm{ml}$ collagenase/dispase, $40 \mu \mathrm{g} / \mathrm{ml}$ DNase I, and $0.147 \mu \mathrm{g} / \mathrm{ml}$ of the protease inhibitor tosyllysine chloromethyl ketone) and incubated at $37^{\circ} \mathrm{C}$ for 75 min with occasional agitation. The suspension was centrifuged at $3800 \times g$. The supernatant was discarded; the pellet was resuspended in prewarmed $\left(37^{\circ} \mathrm{C}\right) \mathrm{PBS}$ and centrifuged at $3800 \times \mathrm{g}$. The pellet was suspended in full medium (DMEM-F12 medium containing 10\% plasma-derived serum, L-glutamine, $1 \%$ antibiotic-antimycotic, $100 \mathrm{mg} / \mathrm{ml}$ heparin, and $100 \mathrm{mg} / \mathrm{ml}$ endothelial cell growth supplement). The resulting capillary fragments were plated onto tissue culture dishes coated with murine collagen IV $(50 \mu \mathrm{g} / \mathrm{ml})$ at a density corresponding to one brain per $9.5 \mathrm{~cm}^{2}$. Medium was exchanged after 24 and $48 \mathrm{~h}$. Puromycin $(8 \mu \mathrm{g} / \mathrm{ml})$ was added to the medium for the first $2 \mathrm{~d}$. Before analysis, the primary mouse brain endothelial cells were grown until the culture reached complete confluence after 5-7 d in vitro.

Cell culture and quantitative reverse transcription PCR. Bend. 3 mouse BECs (ATCC) were grown in ATCC-formulated DMEM supplemented with $10 \%$ FBS. Using TRIzol (Invitrogen), RNA was isolated. cDNA was synthesized using Multiscribe reverse transcriptase (Applied Biosystems). Primers (available upon request) for ARs and CD73 were used to determine gene expression and standardized to TBP gene levels using Kapa Sybr Fast (Kapa Biosystems) run on a Bio-Rad CFX96 real-time quantitative PCR (qPCR) system. Melt curve analyses were performed to measure the specificity for each qPCR product.

Adenosine receptor Western blotting and immunofluorescent analysis. Primary mouse brain endothelial cells and Bend. 3 cell cultures were grown as described above. Cells were lysed with $1 \mathrm{ml}$ of lysis buffer containing protease inhibitor and condensed with TCA solution up to $200 \mu$ l. Samples were run on a 12\% SDS-PAGE and transferred to nitrocellulose paper. Membranes were blocked with $1 \%$ polyvinyl pyrrolidone and incubated with anti- $\mathrm{A}_{1} \mathrm{AR}$ (AAR-006) and - $\mathrm{A}_{2 \mathrm{~A}}$ AR (AAR-002) primary antibodies (Alomone Labs) overnight. The membranes were washed and then incubated with goat anti-rabbit HRP. Membranes were washed thoroughly and developed with ECL solution and exposed to $\mathrm{x}$-ray film. For adenosine receptor immunostaining, anesthetized mice were perfused with PBS and brains were isolated and snap frozen in Tissue Tek-OCT medium. Sections $(5 \mu \mathrm{m}$; brains in a sagittal orientation) were affixed to Superfrost/Plus slides (Fisher Scientific), fixed in acetone, and stored at $-80^{\circ} \mathrm{C}$. Slides were thawed, washed in PBS, blocked with casein (Vector Laboratories) in normal goat serum (Zymed), and then incubated with anti-CD31 (MEC 13.3, BD Biosciences) and anti- $\mathrm{A}_{1}$ AR (A4104, Sigma) or anti- $\mathrm{A}_{2 \mathrm{~A}}$ AR (AAR-002, Alomone Labs). Slides were then incubated with goat anti-rat Ig Alexa Fluor 488 (Invitrogen) and goat anti-rabbit Ig Texas Red-X (Invitrogen). Sections were mounted with Vectashield mounting medium with DAPI (Vector Laboratories). Images were obtained on a Zeiss Axio Imager M1 fluorescent microscope.

Fluorescence in situ hybridization. For detection of adenosine receptor mRNA in brain endothelium, we performed fluorescence in situ hybridization (FISH) using FITC-labeled CD31 and either biotin-labeled $\mathrm{A}_{1}$ or $\mathrm{A}_{2 \mathrm{~A}}$ DNA oligonucleotide probes (Integrated DNA Technologies, probe sequences available upon request). Anesthetized mice were perfused with PBS and brains were isolated and snap frozen in Tissue Tek-OCT medium. Twelve micrometer cryosections were mounted on Superfrost/ Plus slides (Fisher Scientific). After air drying on the slides for $30 \mathrm{~min}$, the tissue was fixed in 4\% neutral buffered PFA for 20 min and rinsed for 3 min in $1 \times$ PBS. Next, the tissue was equilibrated briefly in $0.1 \mathrm{M}$ triethanolamine and acetylated for $10 \mathrm{~min}$ in $0.1 \mathrm{~m}$ triethanolamine with $0.25 \%$ acetic anhydride. Immediately following acetylation, the sections were dehydrated through an ascending ethanol series, and stored at room temperature. The tissue was rehydrated for $2 \times 15 \mathrm{~min}$ in PBS, and equilibrated for $15 \mathrm{~min}$ in $5 \times \operatorname{SSC}(0.75 \mathrm{M} \mathrm{NaCl}, 0.075 \mathrm{M} \mathrm{Na}$-citrate). The sections were then prehybridized for $1 \mathrm{~h}$ at $42^{\circ} \mathrm{C}$ in hybridization buffer (50\% deionized formamide, $4 \times$ SSC, $40 \mu \mathrm{g} / \mathrm{ml}$ salmon sperm DNA, $20 \%$ $(\mathrm{w} / \mathrm{v})$ dextran sulfate, $1 \times$ Denhardt's solution). The probes $(300 \mathrm{ng} / \mathrm{ml})$ were denatured for $3 \mathrm{~min}$ at $80^{\circ} \mathrm{C}$ and added to the prewarmed $\left(42^{\circ} \mathrm{C}\right)$ buffer (hybridization mix). The hybridization reaction was performed at $42^{\circ} \mathrm{C}$ for $38 \mathrm{~h}$ with $250 \mu \mathrm{l}$ of hybridization mix on each slide, covered with Parafilm. Prehybridization and hybridization were performed in a black box saturated with a $4 \times$ SSC-50\% formamide solution to avoid evaporation and photobleaching of FITC. After incubation, the sections were washed for $30 \mathrm{~min}$ in $2 \times$ SSC (room temperature), $15 \mathrm{~min}$ in $2 \times \mathrm{SSC}$ $\left(65^{\circ} \mathrm{C}\right), 15 \mathrm{~min}$ in $0.2 \times \mathrm{SSC}, 0.1 \% \operatorname{SDS}\left(65^{\circ} \mathrm{C}\right)$, and equilibrated for $5 \mathrm{~min}$ in PBS. For detection of the biotin-probes, sections were incubated for 30 min at room temperature with Texas Red X-conjugated streptavidin (Invitrogen, S6370, $1 \mu \mathrm{g} / \mathrm{ml}$ ) in PBS containing $1 \times$ casein (Vector Laboratories). Excess streptavidin was removed by $15 \mathrm{~min}$ in PBS, followed by $15 \mathrm{~min}$ in $0.2 \times \mathrm{SSC}, 0.1 \%$ SDS $\left(65^{\circ} \mathrm{C}\right)$, and $15 \mathrm{~min}$ in PBS washes. 
Sections were coverslipped with Vectashield mounting medium with DAPI (Vector Laboratories). Images were acquired using a Zeiss Axio Imager M1 fluorescent microscope.

Injection of anti- $\beta$-amyloid antibodies and immunofluorescent microscopy. WT and transgenic (AD) mice were given $0.08 \mathrm{mg} / \mathrm{kg}$ NECA (i.v.). After $3 \mathrm{~h}, 400 \mu \mathrm{g}$ of antibody to $\beta$-amyloid $(200 \mu \mathrm{l} \mathrm{of} 2 \mathrm{mg} / \mathrm{ml}$; clone $6 \mathrm{E} 10$, Covance) was administered intravenously and the mice rested for $90 \mathrm{~min}$. Mice were anesthetized and perfused (as described above) and brains were placed in OTC and flash-frozen for sectioning. Sagittal sections $(6 \mu \mathrm{m})$ were fixed in acetone, washed in PBS, blocked with casein and incubated with goat anti-mouse Ig Cy5 (Abcam), and then washed with PBS. Sections were mounted with Vectashield Hardset mounting medium with DAPI (Vector Laboratories). Images were obtained on a Zeiss Axio Imager M1 fluorescent microscope.

Transendothelial cell electrical resistance assays. Bend. 3 cells were grown in ATCC-formulated DMEM supplemented with 10\% FBS on 24-well Transwell inserts, $8 \mu \mathrm{m}$ pore size (BD Falcon, BD Biosciences) until a monolayer was established. Transendothelial cell electrical resistance (TEER) was assessed using a Voltohmmeter (EVOMX, World Precision Instruments). Background resistance from unseeded Transwells was subtracted from recorded values to determine absolute TEER values. Change in absolute TEER from time $0\left(t_{0}\right)$ for each individual Transwell was expressed as percentage change and then averaged for each treatment group.

F-actin staining of endothelial cells. Bend. 3 cells were grown (as described above) on circular coverslips in 24-well plates. Cells were treated for 3 or 30 min with $1 \mu \mathrm{M}$ CCPA, $1 \mu \mathrm{M}$ Lexiscan, DMSO or media alone. Coverslips were washed with PBS, fixed in $4 \%$ paraformaldehyde, washed again in PBS and then permeabilized with $0.5 \%$ Triton X-100 in PBS. After washing in PBS/1\% BSA, coverslips were blocked with $1 \%$ BSA then stained with phalloidin-Alexa Fluor 568. Coverslips were washed and mounted on slides with ProlongGold containing DAPI (Invitrogen). Images were obtained on an Olympus BX51 fluorescent microscope.

Albumin uptake assay. Bend.3 cells grown on collagen-coated coverslips were incubated with albumin-Alexa Fluor $594(50 \mathrm{mg} / \mathrm{ml})$ (Invitrogen) and either medium alone, DMSO vehicle, NECA (1 $\mu \mathrm{M})$, or Lexiscan $(1 \mu \mathrm{M})$ for $30 \mathrm{~min}$. Albumin uptake was visualized (albumin $=$ red) using the Zeiss Axio Imager M1 fluorescent microscope. Total albumin fluorescence was recorded using Zeiss AxioVision software, and measured using Image $(\mathrm{NIH})$ software.

Tight junction molecule staining. Bend.3 cells grown on collagencoated coverslips were incubated with DMSO vehicle, NECA $(1 \mu \mathrm{M})$, or Lexiscan $(1 \mu \mathrm{M})$ for $1 \mathrm{~h}$. Cells were washed with PBS, fixed with $4 \%$ paraformaldehyde, and permeabilized with $0.5 \%$ Triton-X in PBS. Cells were blocked with PBS/BSA/goat serum and then stained with antibodies (Invitrogen) against either ZO-1 (1A12), Claudin-5 (34-1600), or Occludin (3F10). Following a wash step, cells were incubated with either goat anti-rabbit Ig Texas Red-X or goat anti-mouse Ig Cy5 (Invitrogen). Coverslips were washed and mounted on slides with ProlongGold containing DAPI. Images were obtained on a Zeiss Axio Imager M1 fluorescent microscope.

Statistical analyses. Statistical differences, assessed using the Student's $t$ test, are indicated where $p \leq 0.05$.

\section{Results}

The broad-spectrum AR agonist NECA increases BBB permeability to macromolecules

We established that intravenous administration of NECA, which activates all ARs $\left(A_{1}, A_{2 A}, A_{2 B}, A_{3}\right)$, resulted in a dose-dependent increase in extravasation of intravenously administered fluorescently labeled dextrans into the CNS of mice (Fig. 1). Importantly, varying the dose of NECA resulted in dose-dependent increases in CNS entry of both $10 \mathrm{kDa}$ dextrans (Fig. $1 \mathrm{~A}$ ) and 70 $\mathrm{kDa}$ dextrans (Fig. $1 \mathrm{~B}$ ) compared with treatment of vehicle alone. Maximum entry of dextrans into the CNS occurred with 0.08 $\mathrm{mg} / \mathrm{kg}$ NECA. Higher concentrations of NECA had no additional effect or show diminished efficacy, possibly due to receptor desensi-
A

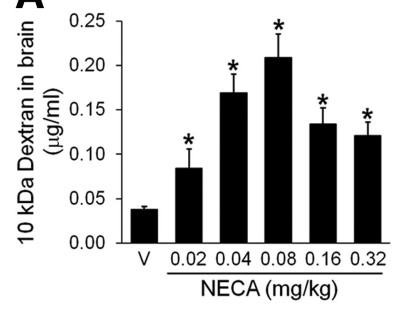

C

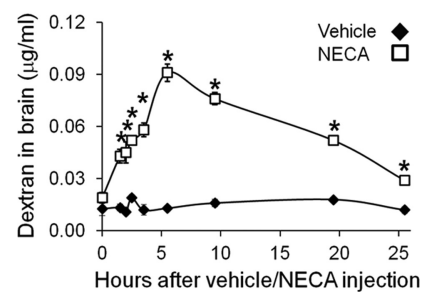

B

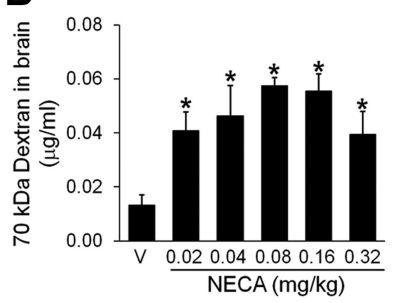

D

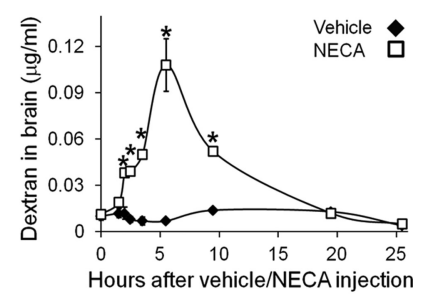

Figure 1. NECA treatment increases BBB permeability in a temporally discrete and reversible manner. $\boldsymbol{A}, \boldsymbol{B}$, Dose-dependent increases in $10 \mathrm{kDa}(\boldsymbol{A})$ and $70 \mathrm{kDa}(\boldsymbol{B})$ dextrans into WT mouse brain $3 \mathrm{~h}$ after intravenous administration of NECA or vehicle as measured by fluorimetry (10 - 15 animals per group). C, Extravasation time course of $10 \mathrm{kDa}$ FITC-dextran into WT mouse brain when coadministered intravenously with NECA $(0.08 \mathrm{mg} / \mathrm{kg})$ or vehicle, as measured by fluorimetry (10-15 animals per group). D, Extravasation time course of $10 \mathrm{kDa}$ Texas Reddextran, administered intravenously 90 min before harvest times (as displayed), into WT mouse brain tissue after intravenous pretreatment (time $=0)$ with NECA $(0.08 \mathrm{mg} / \mathrm{kg})$ or vehicle, as measured by fluorimetry (3-5 animals per group). Data are splined scatter plots with scaled time on the $x$-axis. Experiments were performed at least twice. ${ }^{*} p \leq 0.05$, significant differences (Student's $t$ test) from vehicle. Data are mean \pm SEM.

tization (Ferguson et al., 2000). These results demonstrate that AR activation increases BBB permeability.

We next determined the duration and kinetics of increased BBB permeability after NECA administration. In time course experiments using the maximum effective dose of NECA determined by our dose-response experiments $(0.08 \mathrm{mg} / \mathrm{kg})$, we observed that increased barrier permeability following NECA treatment is temporally discrete (Fig. $1 C$ ), with maximum entry of labeled dextran into the CNS between 4 and $6 \mathrm{~h}$ posttreatment. These data represent accumulation of FITC-dextran in the brain over time, since the dextran and NECA were administered at $t_{0}$. To determine how much dextran can enter the brain in a discrete period of time after NECA treatment, dextran was administered at different times after NECA administration (Fig. $1 D$ ). These data represent dextran entry into the brain $90 \mathrm{~min}$ after dextran injection. At $8 \mathrm{~h}$ post-NECA treatment, detectable levels of dextran in the brain decreased from the maximum and by $18 \mathrm{~h}$ post-treatment the levels returned to baseline, as dextrans administered $18 \mathrm{~h}$ after NECA treatment were not detectable in the brain at significant levels (Fig. 1D). These results demonstrate that intravenous NECA administration results in a temporally discrete period of increased barrier permeability that returns to baseline by $8-18 \mathrm{~h}$.

\section{$A_{1}$ and $A_{2 A} A R$ activation increases $B B B$ permeability}

As AR activation increases $\mathrm{BBB}$ permeability to dextrans in mice, we next determined whether receptors for adenosine are expressed by mouse BECs. Utilizing antibodies and probes against the $A_{1}$ and $A_{2 A} A R s$, we observed expression of both ARs on CD31 costained endothelial cells within the brains of mice by immunofluorescent staining (Fig. $2 \mathrm{~A}$ ) and fluorescence in situ hybridization (Fig. $2 \mathrm{~B}$ ). Importantly, both $\mathrm{A}_{1}$ and $\mathrm{A}_{2 \mathrm{~A}}$ AR protein 
A

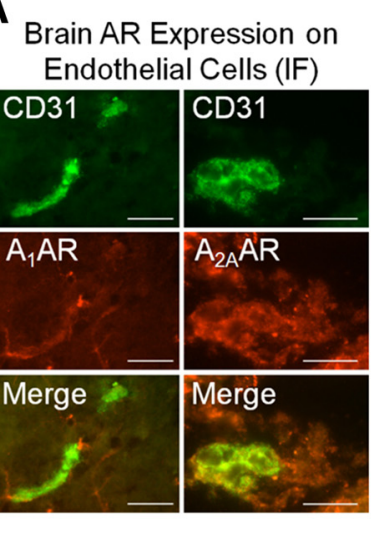

D

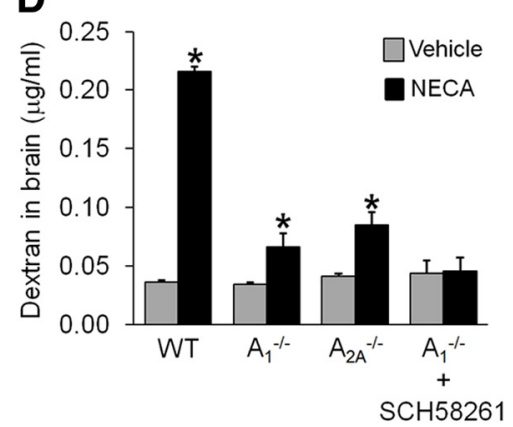

$\mathbf{F}$

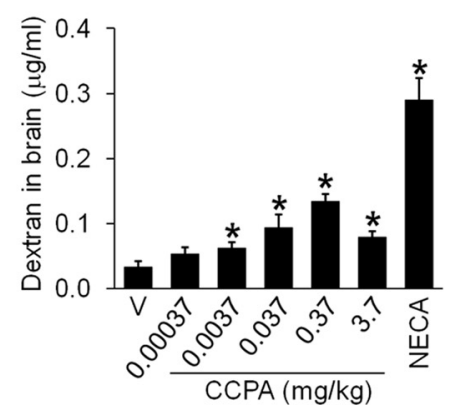

C Brain AR Expression on
Endothelial Cells (FISH) $\begin{array}{rr}\text { CD31 } & \\ & \\ & -\end{array}$

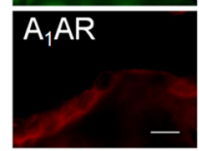
CD31
$A_{2 A} A R$

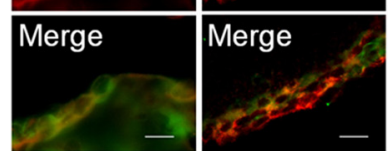

E

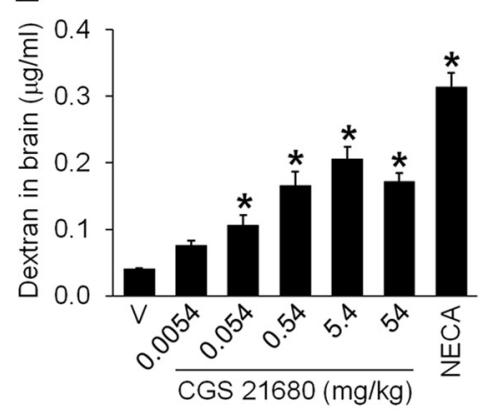

G

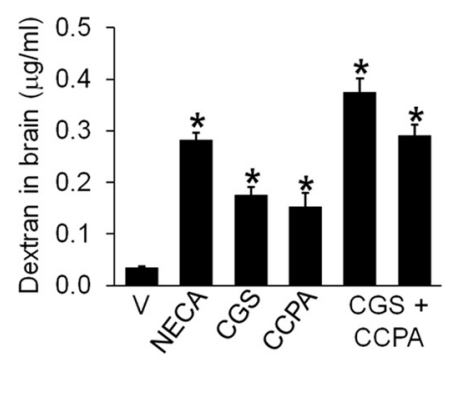

Figure 2. Increased $B B B$ permeability depends on selective agonism of $A_{1}$ and $A_{2 A} A R s . A, B$, Immunofluorescent staining $(\boldsymbol{A})$ and fluorescence in situ hybridization (B) of CD31 (endothelial cell marker; green), and $A_{1}$ (left column; red) and $A_{2 A}$ (right column; red) ARs near the cortical area of the brain in naive mice. Scale bar, $20 \mu \mathrm{m}$. C, Western blot analysis of $A_{1}$ (left) and $A_{2 A}$ (right) $A R$ expression in isolated primary $\mathrm{BEC}$ f from naive mice. $\beta$-Actin expression is shown as a loading control. $\boldsymbol{D}$, Decreased levels of dextran in brains of $A_{1}$ and $A_{2 A}$ AR knock-out mice $3 \mathrm{~h}$ after intravenous administration of NECA $(0.08 \mathrm{mg} / \mathrm{kg})$ or vehicle compared with WT mice, as measured by fluorimetry. No significant increase in dextran levels was detected in brains of $A_{1}$ knock-out mice that were pretreated with the selective $A_{2 A}$ antagonist $S C H 58261$ (5-8 animals per group). $E, F$, Dose-dependent entry of $10 \mathrm{kDa}$ FITC-dextran into WT brain tissue $3 \mathrm{~h}$ after intravenous coadministration of CGS 21860 (selective $A_{2 A}$ AR agonist) (E) or CCPA (selective $A_{1}$ AR agonist) $(\boldsymbol{F})$, as measured by fluorimetry. NECA $(0.08 \mathrm{mg} / \mathrm{kg}$ ) was used as a positive control (10 -13 animals per group). G, Levels of $10 \mathrm{kDa}$ FITC-dextran in WT mouse brain tissue $3 \mathrm{~h}$ after intravenous administration of vehicle, NECA $(0.08$ $\mathrm{mg} / \mathrm{kg})$, CGS $21680(0.54 \mathrm{mg} / \mathrm{kg})$, CCPA $(0.37 \mathrm{mg} / \mathrm{kg})$, and in combination [left column, CGS $21680(0.54 \mathrm{mg} / \mathrm{kg})+$ CCPA $(0.37$ $\mathrm{mg} / \mathrm{kg})$; right column CGS $21680(0.54 \mathrm{mg} / \mathrm{kg})+C(\mathrm{CPA}(0.037 \mathrm{mg} / \mathrm{kg})]$ (3- 4 mice per group). Experiments were repeated at least twice. ${ }^{*} p \leq 0.05$, significant differences (Student's $t$ test) from vehicle. Data are mean \pm SEM.

expression was detected by Western blot analysis on primary endothelial cells isolated from the brains of mice (Fig. 2C). Interestingly, the human brain endothelial cell line hCMEC/D3 also expresses both the $A_{1}$ and $A_{2 A}$ ARs (Mills et al., 2011). These data suggest that BECs are capable of directly responding to extracellular adenosine.

To investigate the functional contribution of $\mathrm{A}_{1}$ and $\mathrm{A}_{2 \mathrm{~A}}$ receptors in AR-mediated changes in $\mathrm{BBB}$ permeability, we studied transgenic mice lacking these receptors. Importantly, there were no significant differences in the basal levels of BBB perme- ability to $10 \mathrm{kDa}$ dextrans between WT, $\mathrm{A}_{1}$ $\mathrm{AR}^{-1-}$ and $\mathrm{A}_{2 \mathrm{~A}} \mathrm{AR}^{-1-}$ mice (Fig. 2D). Following intravenous administration of NECA, both $\mathrm{A}_{1} \mathrm{AR}^{-1-}$ and $\mathrm{A}_{2 \mathrm{~A}} \mathrm{AR}^{-1-}$ mice showed significantly lower levels of intravenously administered dextrans in their brains compared with WT mice. To examine the effect of NECA administration on $\mathrm{BBB}$ permeability in mice when neither the $A_{1}$ nor the $A_{2 A} A R$ is available for activation, $\mathrm{A}_{1} \mathrm{AR}^{-1-}$ mice were treated with the selective $\mathrm{A}_{2 \mathrm{~A}}$ antagonist SCH 58261 before NECA administration. When $A_{2 \mathrm{~A}}$ AR signaling was blocked with this antagonist in mice lacking the $A_{1} A R$, no significant increase in $\mathrm{BBB}$ permeability was observed (Fig. 2D). These data suggest that modulation of $\mathrm{BBB}$ permeability is, at least in part, mediated by these two AR subtypes.

To further confirm these results, we used commercially available AR agonists selective for either the $A_{1}$ or the $A_{2 A} A R$. We administered the selective $A_{1}$ agonist CCPA and the selective $A_{2 A}$ agonist CGS 21680 to WT mice. Both CGS 21680 (Fig. $2 E$ ) and CCPA (Fig. $2 F$ ) treatment resulted in increased dextran entry into the CNS. While this increase was substantial compared with vehicle treatment, it was significantly lower than that observed after NECA administration (Figs. 2E,F). However, when used in combination, CCPA and CGS 21680 recapitulated the magnitude of the effect of increased dextran entry into the CNS that was observed after NECA treatment (Fig. 2G). Together, these results suggest that while activation of either the $A_{1}$ or $A_{2 A} A R$ on BECs can facilitate entry of molecules into the CNS, activation of both ARs has an additive effect.

\section{The selective $\mathrm{A}_{2 \mathrm{~A}} \mathrm{AR}$ agonist Lexiscan increases $B B B$ permeability}

To explore the possible therapeutic use of AR agonism to facilitate CNS entry of intravenously administered compounds, we tested a commercially available, FDAapproved AR agonist in our experimental paradigm. The selective $\mathrm{A}_{2 \mathrm{~A}} \mathrm{AR}$ agonist Lexiscan, which has been successfully used in myocardial perfusion imaging in humans (Iskandrian et al., 2007), did indeed increase BBB permeability to $10 \mathrm{kDa}$ dextrans after intravenous administration in mice (Fig. $3 A$ ). Interestingly, dextran was detectable in the brain 5 min following a single Lexiscan injection. Additionally, intravenous administration of Lexiscan also increased BBB permeability in rats (Fig. $3 B$ ). In an injection paradigm intended to mimic continuous infusion of the drug, 3 injections of Lexiscan over $15 \mathrm{~min}$ resulted in dramatically high levels of labeleddextran detected in the brains of rats (Fig. 3B). To examine the duration of Lexiscan's effects on BBB permeability, we deter- 
A

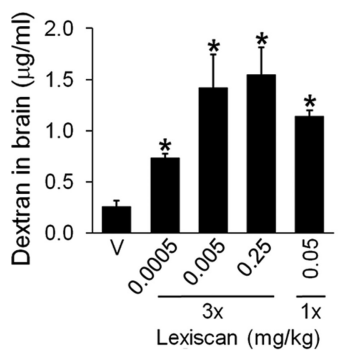

C

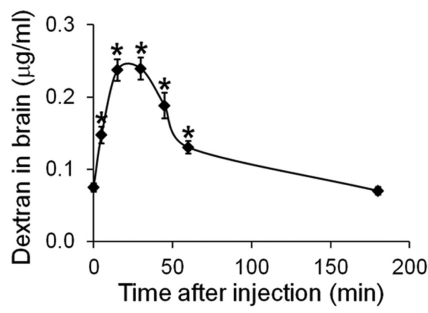

B

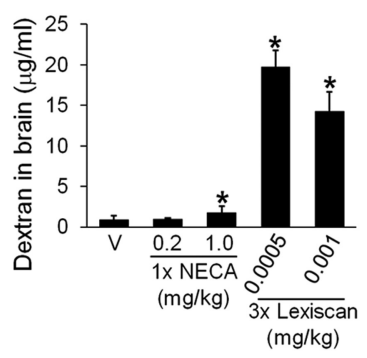

D

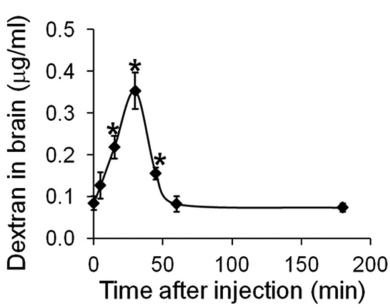

Figure 3. The selective $A_{2 A} A R$ agonist Lexiscan increases $B B B$ permeability in murine models. $\boldsymbol{A}-\boldsymbol{D}$, Lexiscan administration increases $\mathrm{BBB}$ permeability to $10 \mathrm{kDa}$ dextran in mice and rats. See Materials and Methods for experimental design. $A$, Data bars before the line break represent groups that received 3 Lexiscan injections. The bar after the line break represents a group that received a single Lexiscan injection. For the groups receiving 3 injections, perfusion occurred $15 \mathrm{~min}$ after the initial injection. The group that received a single injection was perfused 5 min after injection (10-15 animals per group). Vehicle-treated mice (V) were perfused 15 min after injection. $\boldsymbol{B}$, Lexiscan increases BBB permeability in rats. Animals received 3 injections of Lexiscan, 5 min apart, and were perfused 15 min after the initial injection (3-4 animals per group). As a control reference, animals received 1 injection of NECA and were perfused 15 min after injection. Vehicle-treated mice (V) were perfused 15 min after injection. C, Time course of BBB permeability after Lexiscan treatment in mice. Lexiscan $(0.05 \mathrm{mg} / \mathrm{kg})$ was administered at time 0 (10-14 animals per group). $D$, Time course of BBB permeability after Lexiscan treatment in rats. Lexiscan $(0.0005 \mathrm{mg} / \mathrm{kg})$ was administered at time 0 (3-4 animals per group). All experiments were repeated at least twice. ${ }^{*} p \leq 0.05$, significant differences (Student's $t$ test) from vehicle. Data are mean \pm SEM.

mined CNS dextran entry over time in both mice and rats. Following a single intravenous injection of Lexiscan, maximum increased BBB permeability was observed after $30 \mathrm{~min}$ and returned to baseline by 180 min post-treatment (Fig. 3C). Similar results were observed after Lexiscan treatment in rats (Fig. $3 D$ ). Importantly, the duration of the effects on $\mathrm{BBB}$ permeability after Lexiscan treatment is much shorter than after NECA treatment, probably due to the different half-lives of the compounds [NECA $\sim 5$ h, Lexiscan $\sim 3$ min (Astellas Pharma 2009, Lexiscan: U.S. Physicians Prescribing Information)]. The $>20$-fold increase in labeled-dextran in Figure $3 B$ (compared with single injections, Fig. 3D) may be explained by a synergistic effect conferred on BBB opening as a result of multiple doses of Lexiscan. These results demonstrate that Lexiscan increases BBB permeability to macromolecules.

\section{Antibodies to $\boldsymbol{\beta}$-amyloid enter the brain after NECA administration}

Among the most challenging therapeutic agents to get across the $\mathrm{BBB}$ are macromolecules, such as antibodies, due to their enormous size. We asked whether AR modulation with NECA can facilitate the entry of antibodies into the CNS. To test this, we used a double [amyloid precursor protein (APP)/ presenilin (PSEN)] transgenic mouse model of AD [strain B6. Cg-Tg(APPswe,PSEN1dE9)85Dbo/J]. These mice accumulate $\beta$-amyloid $(\mathrm{A} \beta)$ plaques that are a hallmark of $\mathrm{AD}$ (Jankowsky et
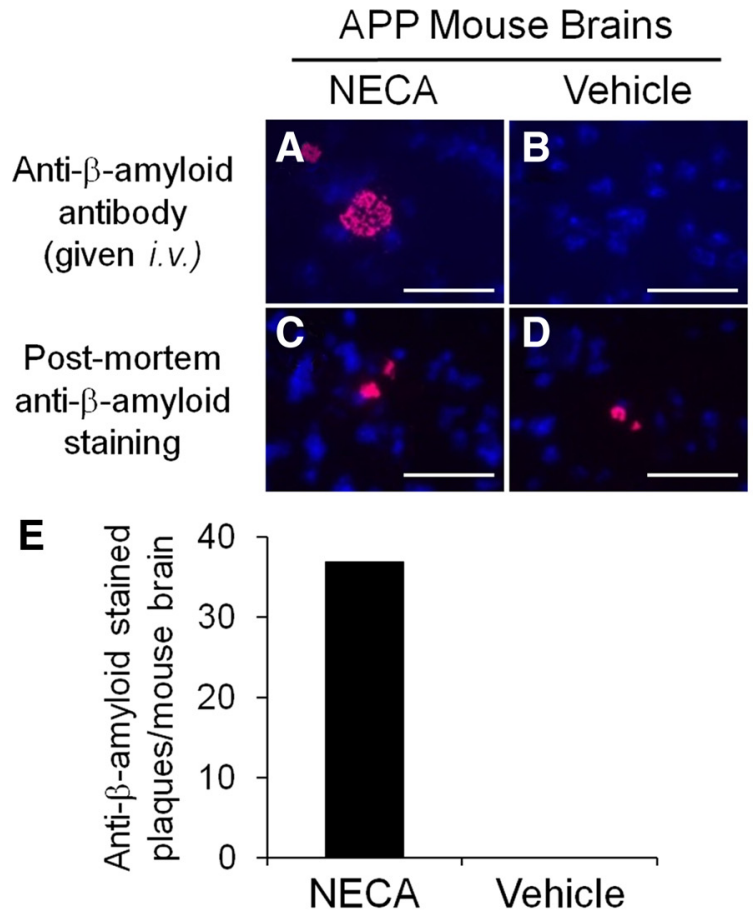

\section{CD31 and $\beta$-amyloid Stained APP Mouse Brains}

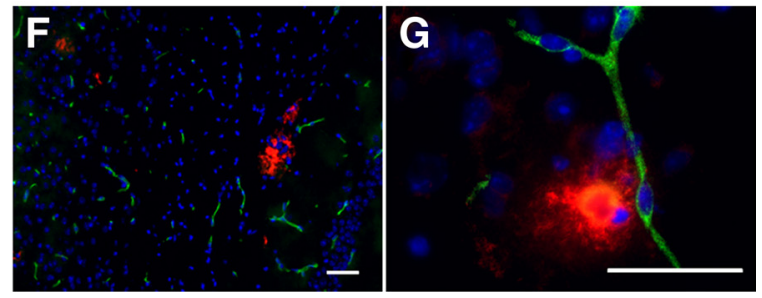

Figure 4. Anti- $\beta$-amyloid antibody administered intravenously crosses the BBB and labels $\beta$-amyloid plaques in transgenic mouse brains after NECA administration. $\boldsymbol{A}-\boldsymbol{D}$, Immunofluorescent microscopic images near the hippocampi of transgenic AD (APP/PSEN) mice. Mice were treated with either $(\boldsymbol{A}, \boldsymbol{C})$ NECA $(0.08 \mathrm{mg} / \mathrm{kg})$ or $(\boldsymbol{B}, \boldsymbol{D})$ vehicle and antibody to $\beta$-amyloid (6E10) was administered intravenously (top; $\boldsymbol{A}, \boldsymbol{B}$ ). For mice that did not receive intravenous $6 \mathrm{E} 10$ antibody (bottom; $\boldsymbol{C}, \boldsymbol{D}), 6 \mathrm{E} 10$ was used as a primary antibody to control for the presence of plaques and was applied ex vivo during immunostaining. Blue, DAPI; red, Cy5-antibody labeling 6E10-labeled $\beta$-amyloid plaques. Scale bar, $50 \mu \mathrm{m}$. E, Quantification of 6E10-labeled amyloid plaques per mouse brain section in transgenic AD mice treated with NECA or vehicle alone. $\boldsymbol{F}, \boldsymbol{G}$, Immunofluorescent microscopic images of the hippocampal and cortical regions from the brains of transgenic AD mice showing an overview $(\boldsymbol{F})$ and close-up $(\boldsymbol{G})$ of $\beta$-amyloid plaque locations relative to blood vessels (endothelial cells are CD31 stained, green; $\beta$-amyloid plaques are 6E10 stained, red; nuclei are DAPI stained, blue). Scale bars, $50 \mu \mathrm{m}$.

al., 2004; Mineur et al., 2005). The monoclonal antibody $6 \mathrm{E} 10$ has been shown to significantly reduce $A \beta$ plaque burden in a mouse model of $\mathrm{AD}$ when administered by intracerebroventricular injection (Thakker et al., 2009). Binding of intravenously injected $6 \mathrm{E} 10$ antibody to $\mathrm{A} \beta$ plaques was observed throughout the brains of NECA-treated AD mice (Fig. $4 A$ ), with a concentration of $\mathrm{A} \beta$ plaques in the hippocampal region. No binding of intravenously injected 6E10 antibody was observed in $\mathrm{AD}$ mice treated with vehicle alone (Fig. $4 B$ ) or in WT mice treated with NECA or vehicle (data not shown). Neither NECA nor vehicle treatment alone affected the ability of $\mathrm{AD}$ mice to form $\mathrm{A} \beta$ plaques (Fig. $4 C, D)$. These results demonstrate that intravenously administered antibody to $\mathrm{A} \beta$ can cross the $\mathrm{BBB}$ following $\mathrm{AR}$ agonism and bind CNS A $\beta$ plaques (Fig. $4 E$ ), most of which are located near blood vessels within the brain (Fig. $4 F, G$ ). 
A

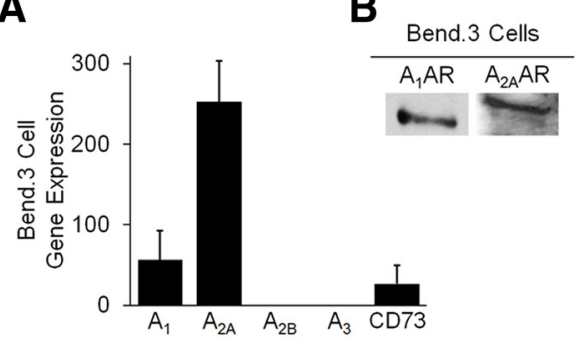

Bend. 3 Cell Albumin Uptake

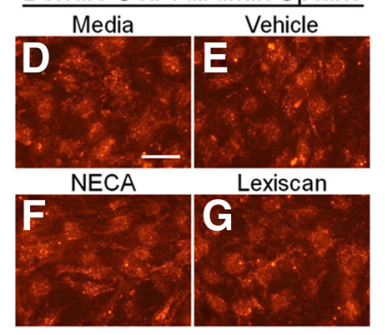

C

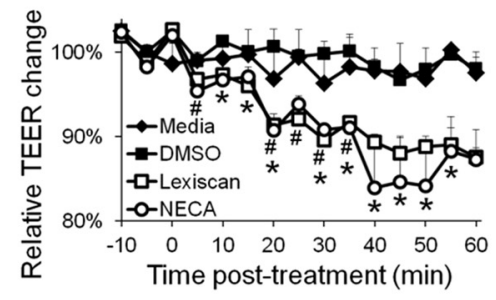

H

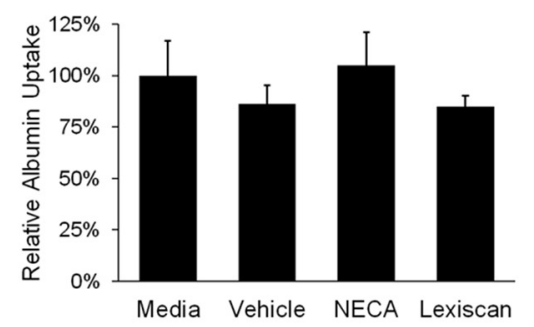

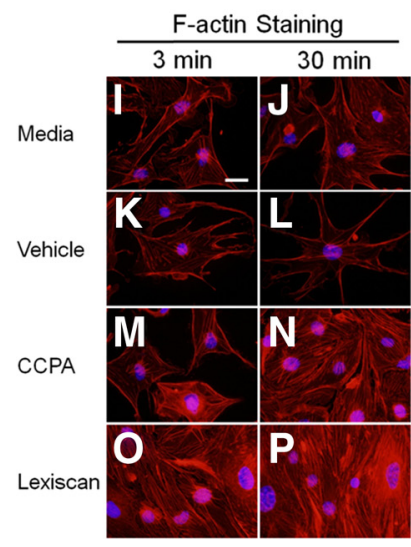

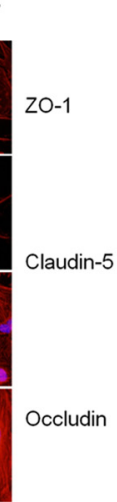

Vehicle

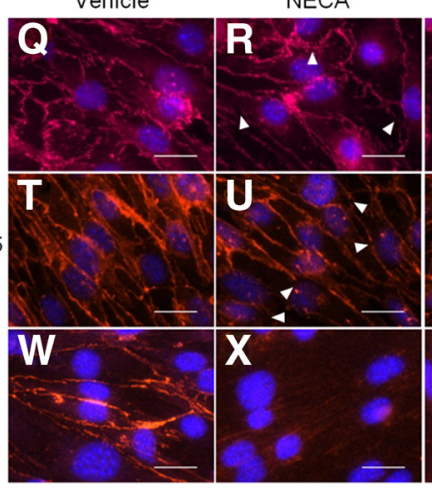

Lexiscan

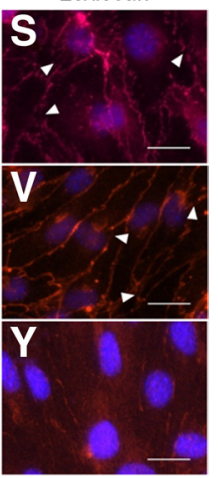

Figure 5. AR signaling results in changes in the paracellular but not transcellular pathway on brain endothelial cells. $A$, Relative genetic expression of ARs subtypes on cultured mouse BECs (Bend.3). $\boldsymbol{B}$, Western blot analysis of $A_{1}$ (left) and $A_{2 A}$ (right) AR expression in cultured mouse BECs (Bend.3). C, AR activation decreases TEER in mouse BEC monolayers. Decreased transendothelial electrical resistance was observed after addition of NECA $(1 \mu \mathrm{M})$ or Lexiscan $(1 \mu \mathrm{M})$ treatment. Significant differences (Student's $\mathrm{s}$ test) from vehicle for Lexiscan, ${ }^{\#} p \leq 0.05$ and NECA, ${ }^{*} p \leq 0.05$. Data are mean \pm SEM. $\boldsymbol{D}-\boldsymbol{H}$, Bend.3 cells were incubated with fluorescently labeled albumin and either media alone $(\boldsymbol{D})$, vehicle $(\boldsymbol{E}), \mathrm{NECA}(1 \mu \mathrm{M})(\boldsymbol{F})$, or Lexiscan $(1 \mu \mathrm{M})(\boldsymbol{G})$ for $30 \mathrm{~min}$. Albumin uptake was visualized by fluorescence microscopy (albumin, red; DAPI-stained nuclei, blue). Scale bar, $50 \mu \mathrm{m}$. $\boldsymbol{H}$, Albumin uptake is displayed as relative values compared with the media-alone control (set to 100\%). Data are mean \pm SEM ( $n=5$ fields per group). I-P, Actinomyosin stress fiber formation correlates with AR activation in cultured BECs. Phalloidin staining of Bend.3 cells reveals increased actinomyosin stress fiber formation following treatment with CCPA $(1 \mu \mathrm{M})(\boldsymbol{M}, \boldsymbol{N})$ or Lexiscan $(1 \mu \mathrm{M})(\mathbf{O}, \boldsymbol{P})$ when compared with media $(\boldsymbol{I}, \boldsymbol{J})$ or vehicle $(\boldsymbol{K}, \boldsymbol{L})$ alone. Left, 3 min treatment; right, 30 min treatment. Scale bar, $50 \mu \mathrm{m} . \mathbf{Q}-\boldsymbol{Y}, \mathrm{AR}$ activation induces changes in tight junction adhesion molecules in cultured BECs. Z0-1 (Q-S), Claudin-5 (T-V), and Occludin $(\boldsymbol{W}-\boldsymbol{Y})$ staining of Bend.3 cells following $1 \mathrm{~h}$ treatment with DMSO (left column), NECA (1 $\mu \mathrm{M}$, middle column), and Lexiscan (1 $\mu \mathrm{M}$, right column). Adhesion molecules are pink/red; DAPI-stained nuclei are blue. Arrowheads indicate examples of discrete changes in expression. Scale bar, $20 \mu \mathrm{m}$.

Bend.3 cells (Fig. 5B), suggesting that these cells are capable of directly responding to extracellular adenosine.

Decreased TEER in endothelial cell monolayers has been demonstrated to correlate with increased paracellular space between endothelial cells and increased barrier permeability (Wójciak-Stothard et al., 2001; Dewi et al., 2004). In Transwell assays with monolayers of cultured mouse BECs (starting absolute TEER mean = $182 \Omega$; median $=187 \Omega$ ), we observed decreases in TEER after addition of NECA or Lexiscan, compared with BECs given vehicle or media alone (Fig. $5 C$ ). While AR signaling alters TEER in BECs, we did not observe any alterations in the rate of transcytosis in BECs following AR stimulation. For instance, NECAand Lexiscan-induced AR signaling did not affect the rate of fluorescently labeled albumin uptake in BECs, compared with media- and vehicle-treated controls (Figs. $5 D-H)$. These results suggest that AR signaling can increase endothelial barrier permeability.

\section{AR activation correlates with actinomyosin stress fiber formation and alterations in tight junctions in BECs}

The actin cytoskeleton is vital for the maintenance of cell shape and for endothelial barrier integrity. Since actinomyosin stress fibers induce changes in cell shape (Hotulainen and Lappalainen, 2006; Prasain and Stevens, 2009), we hypothesized that AR signaling may induce actinomyosin stress fiber formation in BECs. To test this, we treated BECs with agonists selective for either $\mathrm{A}_{1}$ or $\mathrm{A}_{2 \mathrm{~A}}$ ARs (Fig. 5I-P). We observed marked induction of actinomyosin stress fiber formation upon $A_{1} A R$ or $A_{2 A} A R$ agonist treatment (Fig. 5M-P) compared with treatment with media or vehicle alone (Figs. 5I-L). This suggests that activation of ARs induces changes in cytoskeletal elements in BECs to increase barrier permeability.

While AR signaling induces changes in

AR activation results in decreased transendothelial resistance in cultured mouse BEC monolayers

To determine how AR signaling mediates changes in BBB permeability, we used the preestablished mouse brain endothelial cellline, Bend.3 (Montesano et al., 1990). While there are four known AR subtypes expressed in mammals $\left[\mathrm{A}_{1}, \mathrm{~A}_{2 \mathrm{~A}}, \mathrm{~A}_{2 \mathrm{~B}}\right.$ and $\mathrm{A}_{3}$ (Sebastião and Ribeiro, 2009)], mRNA expression of the $A_{1}$ and $A_{2 A}$ receptors, but not $A_{2 B}$ or $A_{3}$ receptors, was detected in Bend. 3 cells (Fig. 5A). Additionally, we observed expression of CD73, an ectoenzyme required for the catalysis of extracellular adenosine from ATP, on these cultured mouse BECs (Fig. 5A). Importantly, protein expression for the $A_{1}$ and $A_{2 A}$ ARs were detected on
TEER, which is a functional measure of paracellular permeability, and actinomyosin stress fibers, which regulate cell shape, it is important to determine whether AR signaling alters the junctional interactions between BECs. Therefore to determine whether AR signaling alters the tight junction of BECs, we cultured Bend. 3 cells to confluent monolayers and determined whether the expression of ZO-1, Claudin-5, or Occludin was altered following AR agonist treatment (Fig. 5Q-Y). While confluent Bend. 3 cells formed proper tight junctions when grown in media (data not shown) or treated with vehicle (Fig. 5Q,T,W), $\mathrm{AR}$ agonist treatment induced alterations in tight junction protein expression. For example, Bend. 3 cells treated with NECA or 

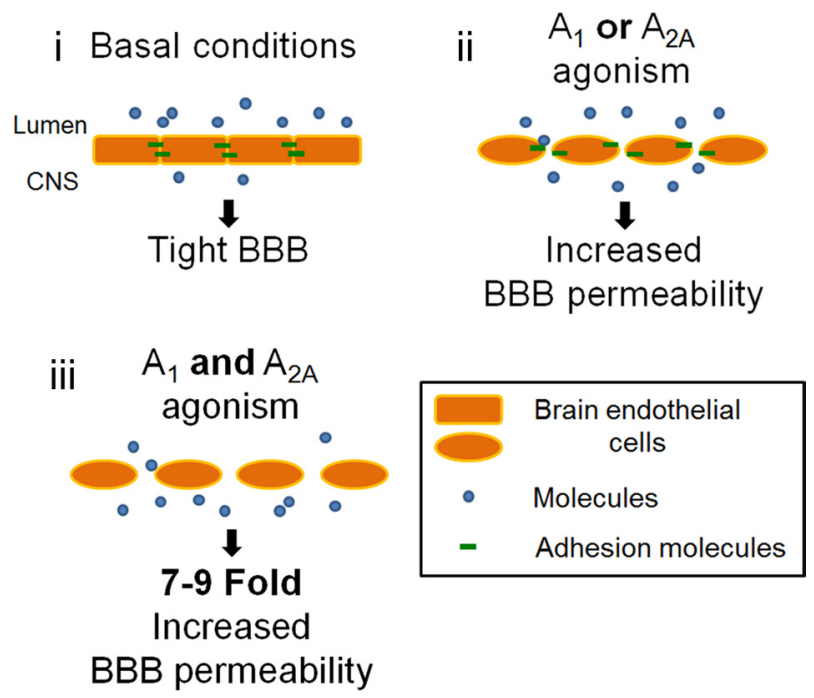

Figure 6. Model of AR signaling and modulation of BBB permeability. $i$, Basal conditions favor a tight barrier. ii, Activation of the $A_{1}$ or $A_{2 A} A R$ results in increased $B B B$ permeability. iii, Activation of both $A_{1}$ and $A_{2 A} A R s$ results in even more permeability than observed after activation of either receptor alone.

Lexiscan had severely diminished Occludin expression (Fig. $5 X, Y$ ) following treatment with discreet alterations in ZO-1 (Fig. $5 R, S$ ) and Claudin-5 (Fig. $5 U, V$ ). Overall, these results strongly suggest BEC permeability can be altered by AR signaling through changes tight junction molecule expression.

\section{Discussion}

We propose that adenosine, acting through the $\mathrm{A}_{1}$ or $\mathrm{A}_{2 \mathrm{~A}}$ receptors, can modulate $\mathrm{BBB}$ permeability to facilitate the entry of molecules into the CNS. Given that adenosine has a relatively short half-life of $<10$ s (Klabunde, 1983), its role as a physiologic modulator is limited to the local environment in which it is produced. Indeed, the expression of CD73 and ARs on BECs suggests these cells have the ability to respond to extracellular ATP, a well established damage signal (Davalos et al., 2005; Haynes et al., 2006). Our findings suggest that AR signaling at the BBB on endothelial cells represents a key event in the "sensing" of damage that would necessitate changes in barrier permeability. The absence of elevated levels of extracellular adenosine favors a tight and restrictive barrier. Activation of either the $A_{1}$ or $A_{2 A} A R$ temporarily increases $\mathrm{BBB}$ permeability, while activation of both receptors results in an additive effect of increased BBB permeability (Fig. 6). Overall, we propose that $\mathrm{BBB}$ permeability mediated through $\mathrm{A}_{1}$ and $\mathrm{A}_{2 \mathrm{~A}}$ ARs operates as a door where activation opens the door and local adenosine concentration is the key.

While the identification of the $A_{1}$ and $A_{2 A}$ ARs as critical mediators of $\mathrm{BBB}$ permeability represents the first step toward a molecular mechanism, much work remains to elucidate the specific downstream players that facilitate cellular changes in the endothelial cells. As mentioned earlier, ARs are G-protein coupled receptors, associated with heterotrimeric G-proteins. Several $G_{\alpha}$ subunits have been localized to tight junctions (Denker et al., 1996). These $G_{\alpha}$ subunits are known to influence the activity of downstream enzymes like RhoA and Racl that have been implicated in cytoskeletal remodeling. Indeed, work by other groups suggests that the RhoA and Racl small GTPases are responsive to extracellular adenosine signaling and mediate changes in the actin cytoskeleton (Jou et al., 1998; Wójciak-Stothard et al., 2001; Schreibelt et al., 2007). Additionally, evidence suggests that aden- osine affects actin through Rho GTPase (Sohail et al., 2009). Importantly, inflammation caused by canonical damage signals like TNF- $\alpha$ and thrombin increases BBB permeability by altering tight junctions through cytoskeletal reorganization (Lum and Malik, 1996; Wójciak-Stothard et al., 1998). We propose that signaling events initiated by activation of $\mathrm{A}_{1}$ and $\mathrm{A}_{2 \mathrm{~A}}$ ARs on BECs induce similar cytoskeletal remodeling which, by changing cell shape and/or size, increases the space between endothelial cells and allows greater molecular diffusion. Indeed, adenosine has been shown to affect the barrier properties of other endothelial cells in a similar manner (Lu et al., 2010). Supporting this, we observed actinomyosin stress fiber formation in BEC monolayers upon $A_{1}$ or $A_{2 A} A R$ activation with selective agonists. This strongly correlates AR activation with stress fiber formation. Together with our observations that $\mathrm{AR}$ agonists also decrease TEER in BEC monolayers, it suggests that AR modulation, acting through cytoskeletal elements, causes changes in endothelial cell shape that increase barrier permeability. In addition, treatment of cultured BECs with the broad AR agonist NECA and the selective $A_{2 A}$ AR agonist Lexiscan did not significantly change albumin transcytosis when compared with vehicle treatment alone. However, NECA and Lexiscan did alter tight junction adhesion molecule expression (Occludin) on BECs. Future studies will seek to define the molecular mechanisms underlying these events. These studies include elucidating the molecular biology of AR activation on tight junction complex proteins on BEC's permeability both in vivo and in vitro.

There is great need for a safe and effective method to facilitate the entry of drugs across the BBB for treatment of neurological disorders. Current strategies for CNS drug-delivery fall into three broad categories: chemical or physical BBB disruption and drug modification (Pardridge, 2005). Methods for chemically disrupting the $\mathrm{BBB}$ vary. Hypertonic mannitol osmotically shrinks brain endothelial cells, thus increasing BBB permeability and facilitating CNS delivery of chemotherapeutics (Newel et al., 1979). However, it has been demonstrated that this procedure carries the risk of inducing epileptic seizures (Newel et al., 1983; Marché et al., 2007). An analog of the vasoactive peptide bradykinin was shown to increase permeability of the blood-tumor barrier (Raymond et al., 1986), and to some extent the BBB (Borlongan and Emerich, 2003), and was moderately effective in increasing hydrophilic, but not lipophilic, drug delivery to certain CNS gliomas in rat models (Bartus et al., 1996; Elliott et al., 1996; Matsukado et al., 1996; Emerich et al., 1999). However, it failed in clinical trials, due possibly to differences between rat models and human patients (Prados et al., 2003).

Physical disruption of the barrier is the oldest and most invasive method of by-passing a functional BBB. Direct injections into the brain, especially into the ventricles, have been used for years to deliver therapeutics to the CNS (Cook et al., 2009). Recently, high-intensity focused ultrasound technologies have been developed that forcefully push therapeutic compounds past the BBB using compression waves (Bradley, 2009). Still, physically disrupting the $\mathrm{BBB}$ remains invasive.

Drugs that do not cross the BBB can sometimes be modified to allow them to cross. The addition of moieties that increase a drug's lipophilicity can increase the likelihood it will cross the $\mathrm{BBB}$, but these additions also render the drug more capable of entering all cell types (Witt et al., 2001). It is also often the case that the chemical additions themselves significantly increase the size of the drug which counteracts the higher lipophilic profile (Witt et al., 2001). Another approach involves so-called "vectorbased" technologies in which the drug in attached to a compound 
known to enter the CNS through receptor-mediated endocytosis. For example, conjugation of neuronal growth factor (NGF) to a monoclonal antibody to the transferrin receptor, expressed on BECs, greatly increased NGF delivery to rat brains (Granholm et al., 1994). Vector-based delivery technologies suffer from two large drawbacks: (1) the BBB transport ability is limited to receptor expression and (2) endocytotic events are limited in BBB endothelium, a hallmark of its physiology.

Our findings in this study suggest AR signaling represents a novel endogenous mechanism for controlling BBB permeability and a potentially useful alternative to existing CNS drug-delivery technologies. Drugs like Lexiscan, the FDA-approved $\mathrm{A}_{2 \mathrm{~A}} \mathrm{AR}$ agonist, which increases $\mathrm{BBB}$ permeability and facilitates CNS entry of macromolecules like dextrans, represent a possible pathway toward future therapeutic applications in humans. Interestingly, the duration of increased $\mathrm{BBB}$ permeability seems to correlate with the half-life of the AR agonist. For example, the time course of BBB opening and closing after treatment with NECA (half-life $\sim 5 \mathrm{~h}$; data not shown) is much longer than the time course after treatment with Lexiscan [half-life $\sim 3$ min (Astellas Pharma, 2009, Lexiscan: U.S. Physicians Prescribing Information)]. Importantly, our findings suggest this technique could be used for CNS delivery of macromolecular therapeutics like antibodies, which traditionally have been limited in their use in treating neurological diseases because they required invasive delivery technologies (Thakker et al., 2009). The authors acknowledge that modulating BBB permeability through AR signaling and allowing temporary CNS access to molecules and compounds in circulation is not a trivial proposition. On-going studies by our laboratory aim to elucidate further the molecular mechanisms involved in changing BBB permeability through AR signaling and to refine this system for delivery of therapeutic compounds into the CNS. Indeed, determining proper timing and control of BBB permeability will be crucial for developing therapeutic strategies based on this discovery. Studies are underway to determine exactly where in the brain microvasculature AR-induced changes in BBB permeability are occurring and whether these processes are local or global in the brain. Nevertheless, the results described here represent a novel and promising alternative to existing CNS drug-delivery paradigms.

\section{References}

Abbott NJ, Patabendige AA, Dolman DE, Yusof SR, Begley DJ (2010) Structure and function of the blood-brain barrier. Neurobiol Dis 37:13-25.

Bartus RT, Elliott P, Hayward N, Dean R, McEwen EL, Fisher SK (1996) Permeability of the blood brain barrier by the bradykinin agonist, RMP-7: evidence for a sensitive, auto-regulated, receptor-mediated system. Immunopharmacology 33:270-278.

Bidros DS, Vogelbaum MA (2009) Novel drug delivery strategies in neurooncology. Neurotherapeutics 6:539-546.

Borlongan CV, Emerich DF (2003) Facilitation of drug entry into the CNS via transient permeation of blood brain barrier: laboratory and preliminary clinical evidence from bradykinin receptor agonist, Cereport. Brain Res Bull 60:297-306.

Bours MJ, Swennen EL, Di Virgilio F, Cronstein BN, Dagnelie PC (2006) Adenosine $5^{\prime}$-triphosphate and adenosine as endogenous signaling molecules in immunity and inflammation. Pharmacol Ther 112:358-404.

Bradley WG Jr (2009) MR-guided focused ultrasound: a potentially disruptive technology. J Am Coll Radiol 6:510-513.

Broadwell RD, Salcman M, Kaplan RS (1982) Morphologic effect of dimethyl sulfoxide on the blood-brain barrier. Science 217:164-166.

Chen JF, Huang Z, Ma J, Zhu J, Moratalla R, Standaert D, Moskowitz MA, Fink JS, Schwarzschild MA (1999) A(2A) adenosine receptor deficiency attenuates brain injury induced by transient focal ischemia in mice. J Neurosci 19:9192-9200.
Cook AM, Mieure KD, Owen RD, Pesaturo AB, Hatton J (2009) Intracerebroventricular administration of drugs. Pharmacotherapy 29:832-845.

Davalos D, Grutzendler J, Yang G, Kim JV, Zuo Y, Jung S, Littman DR, Dustin ML, Gan WB (2005) ATP mediates rapid microglial response to local brain injury in vivo. Nat Neurosci 8:752-758.

Deaglio S, Dwyer KM, Gao W, Friedman D, Usheva A, Erat A, Chen JF, Enjyoji K, Linden J, Oukka M, Kuchroo VK, Strom TB, Robson SC (2007) Adenosine generation catalyzed by CD39 and CD73 expressed on regulatory $\mathrm{T}$ cells mediates immune suppression. J Exp Med 204:1257-1265.

Denker BM, Saha C, Khawaja S, Nigam SK (1996) Involvement of a heterotrimeric $\mathrm{G}$ protein alpha subunit in tight junction biogenesis. J Biol Chem 271:25750-25753.

Dewi BE, Takasaki T, Kurane I (2004) In vitro assessment of human endothelial cell permeability: effects of inflammatory cytokines and dengue virus infection. J Virol Methods 121:171-180.

Elliott PJ, Hayward NJ, Dean RL, Blunt DG, Bartus RT (1996) Intravenous RMP-7 selectively increases uptake of carboplatin into rat brain tumors. Cancer Res 56:3998-4005.

Emerich DF, Snodgrass P, Dean R, Agostino M, Hasler B, Pink M, Xiong H, Kim BS, Bartus RT (1999) Enhanced delivery of carboplatin into brain tumours with intravenous Cereport (RMP-7): dramatic differences and insight gained from dosing parameters. Br J Cancer 80:964-970.

Ferguson G, Watterson KR, Palmer TM (2000) Subtype-specific kinetics of inhibitory adenosine receptor internalization are determined by sensitivity to phosphorylation by $\mathrm{G}$ protein-coupled receptor kinases. Mol Pharmacol 57:546-552.

Granholm AC, Bäckman C, Bloom F, Ebendal T, Gerhardt GA, Hoffer B, Mackerlova L, Olson L, Söderström S, Walus LR, Friden PM (1994) NGF and anti-transferrin receptor antibody conjugate: short and longterm effects on survival of cholinergic neurons in intraocular septal transplants. J Pharmacol Exp Ther 268:448-459.

Hanig JP, Morrison JM Jr, Krop S (1972) Ethanol enhancement of bloodbrain barrier permeability to catecholamines in chicks. Eur J Pharmacol 18:79-82.

Haynes SE, Hollopeter G, Yang G, Kurpius D, Dailey ME, Gan WB, Julius D (2006) The P2Y12 receptor regulates microglial activation by extracellular nucleotides. Nat Neurosci 9:1512-1519.

Hotulainen P, Lappalainen P (2006) Stress fibers are generated by two distinct actin assembly mechanisms in motile cells. J Cell Biol 173:383-394.

Hynynen K (2010) MRI-guided focused ultrasound treatments. Ultrasonics 50:221-229.

Iskandrian AE, Bateman TM, Belardinelli L, Blackburn B, Cerqueira MD, Hendel RC, Lieu H, Mahmarian JJ, Olmsted A, Underwood SR, Vitola J, Wang W (2007) Adenosine versus regadenoson comparative evaluation in myocardial perfusion imaging: results of the ADVANCE phase 3 multicenter international trial. J Nucl Cardiol 14:645-658.

Jankowsky JL, Fadale DJ, Anderson J, Xu GM, Gonzales V, Jenkins NA, Copeland NG, Lee MK, Younkin LH, Wagner SL, Younkin SG, Borchelt DR (2004) Mutant presenilins specifically elevate the levels of the 42 residue beta-amyloid peptide in vivo: evidence for augmentation of a 42 -specific gamma secretase. Hum Mol Genet 13:159-170.

Jou TS, Schneeberger EE, Nelson WJ (1998) Structural and functional regulation of tight junctions by RhoA and Racl small GTPases. J Cell Biol 142:101-115.

Klabunde RE (1983) Dipyridamole inhibition of adenosine metabolism in human blood. Eur J Pharmacol 93:21-26.

Kobie JJ, Shah PR, Yang L, Rebhahn JA, Fowell DJ, Mosmann TR (2006) T regulatory and primed uncommitted CD4 T cells express CD73, which suppresses effector $\mathrm{CD} 4 \mathrm{~T}$ cells by converting $5^{\prime}$-adenosine monophosphate to adenosine. J Immunol 177:6780-6786.

Lu Q, Harrington EO, Newton J, Casserly B, Radin G, Warburton R, Zhou Y, Blackburn MR, Rounds S (2010) Adenosine protected against pulmonary edema through transporter- and receptor A2-mediated endothelial barrier enhancement. Am J Physiol Lung Cell Mol Physiol 298:L755-L767.

Lum H, Malik AB (1996) Mechanisms of increased endothelial permeability. Can J Physiol Pharmacol 74:787-800.

Marchi N, Angelov L, Masaryk T, Fazio V, Granata T, Hernandez N, Hallene K, Diglaw T, Franic L, Najm I, Janigro D (2007) Seizure-promoting effect of blood-brain barrier disruption. Epilepsia 48:732-742.

Matsukado K, Inamura T, Nakano S, Fukui M, Bartus RT, Black KL (1996) Enhanced tumor uptake of carboplatin and survival in glioma-bearing 
rats by intracarotid infusion of bradykinin analog, RMP-7. Neurosurgery 39:125-133.

Mills JH, Thompson LF, Mueller C, Waickman AT, Jalkanen S, Niemela J, Airas L, Bynoe MS (2008) CD73 is required for efficient entry of lymphocytes into the central nervous system during experimental autoimmune encephalomyelitis. Proc Natl Acad Sci U S A 105:9325-9330.

Mills JH, Alabanza L, Weksler BB, Couraud PO, Romero IA, Bynoe MS (2011) Human brain endothelial cells are responsive to adenosine receptor activation. Purinergic Signal 7:265-273.

Mineur YS, McLoughlin D, Crusio WE, Sluyter F (2005) Genetic mouse models of Alzheimer's disease. Neural Plast 12:299-310.

Montesano R, Pepper MS, Möhle-Steinlein U, Risau W, Wagner EF, Orci L (1990) Increased proteolytic activity is responsible for the aberrant morphogenetic behavior of endothelial cells expressing the middle T oncogene. Cell 62:435-445.

Neuwelt EA, Frenkel EP, Diehl JT, Maravilla KR, Vu LH, Clark WK, Rapoport SI, Barnett PA, Hill SA, Lewis SE, Ehle AL, Beyer CW Jr, Moore RJ (1979) Osmotic blood-brain barrier disruption: a new means of increasing chemotherapeutic agent delivery. Trans Am Neurol Assoc 104:256-260.

Neuwelt EA, Specht HD, Howieson J, Haines JE, Bennett MJ, Hill SA, Frenkel EP (1983) Osmotic blood-brain barrier modification: clinical documentation by enhanced CT scanning and/or radionuclide brain scanning. AJR Am J Roentgenol 141:829-835.

Pardridge WM (2001) Brain drug targeting: the future of brain drug development. Cambridge, UK: Cambridge UP.

Pardridge WM (2005) The blood-brain barrier: bottleneck in brain drug development. NeuroRx 2:3-14.

Prados MD, Schold SJ, Fine HA, Jaeckle K, Hochberg F, Mechtler L, Fetell MR, Phuphanich S, Feun L, Janus TJ, Ford K, Graney W (2003) A randomized, double-blind, placebo-controlled, phase 2 study of RMP-7 in combination with carboplatin administered intravenously for the treatment of recurrent malignant glioma. Neuro Oncol 5:96-103.

Prasain N, Stevens T (2009) The actin cytoskeleton in endothelial cell phenotypes. Microvasc Res 77:53-63.

Rapoport SI (2001) Advances in osmotic opening of the blood-brain barrier to enhance CNS chemotherapy. Expert Opin Investig Drugs 10:1809-1818.

Raymond JJ, Robertson DM, Dinsdale HB (1986) Pharmacological modification of bradykinin induced breakdown of the blood-brain barrier. Can J Neurol Sci 13:214-220.
Schreibelt G, Kooij G, Reijerkerk A, van Doorn R, Gringhuis SI, van der Pol S, Weksler BB, Romero IA, Couraud PO, Piontek J, Blasig IE, Dijkstra CD, Ronken E, de Vries HE (2007) Reactive oxygen species alter brain endothelial tight junction dynamics via RhoA, PI3 kinase, and PKB signaling. FASEB J 21:3666-3676.

Sebastião AM, Ribeiro JA (2009) Adenosine receptors and the central nervous system. Handb Exp Pharmacol 193:471-534.

Sohail MA, Hashmi AZ, Hakim W, Watanabe A, Zipprich A, Groszmann RJ, Dranoff JA, Torok NJ, Mehal WZ (2009) Adenosine induces loss of actin stress fibers and inhibits contraction in hepatic stellate cells via Rho inhibition. Hepatology 49:185-194.

Song L, Pachter JS (2003) Culture of murine brain microvascular endothelial cells that maintain expression and cytoskeletal association of tight junction-associated proteins. In Vitro Cell Dev Biol Anim 39:313-320.

Stone TW, Ceruti S, Abbracchio MP (2009) Adenosine receptors and neurological disease: neuroprotection and neurodegeneration. Handb Exp Pharmacol 193:535-587.

Sun D, Samuelson LC, Yang T, Huang Y, Paliege A, Saunders T, Briggs J, Schnermann J (2001) Mediation of tubuloglomerular feedback by adenosine: evidence from mice lacking adenosine 1 receptors. Proc Natl Acad Sci U S A 98:9983-9988.

Thakker DR, Weatherspoon MR, Harrison J, Keene TE, Lane DS, Kaemmerer WF, Stewart GR, Shafer LL (2009) Intracerebroventricular amyloid-beta antibodies reduce cerebral amyloid angiopathy and associated microhemorrhages in aged Tg2576 mice. Proc Natl Acad Sci U S A 106:4501-4506.

Thompson LF, Eltzschig HK, Ibla JC, Van De Wiele CJ, Resta R, MoroteGarcia JC, Colgan SP (2004) Crucial role for ecto-5'-nucleotidase (CD73) in vascular leakage during hypoxia. J Exp Med 200:1395-1405.

Witt KA, Gillespie TJ, Huber JD, Egleton RD, Davis TP (2001) Peptide drug modifications to enhance bioavailability and blood-brain barrier permeability. Peptides 22:2329-2343.

Wójciak-Stothard B, Entwistle A, Garg R, Ridley AJ (1998) Regulation of TNF-alpha-induced reorganization of the actin cytoskeleton and cell-cell junctions by Rho, Rac, and Cdc42 in human endothelial cells. J Cell Physiol 176:150-165.

Wójciak-Stothard B, Potempa S, Eichholtz T, Ridley AJ (2001) Rho and Rac but not Cdc42 regulate endothelial cell permeability. J Cell Sci 114:13431355. 